\title{
Infective endocarditis in the 21st century
}

Infective endocarditis (IE) is a consequence of the localized or systemic diffusion of pathogens, generally bacteria or fungi, in the heart $(1,2)$. Complications of heart valve endocarditis (HVE) develops in approximately from $1 \%$ to $43 \%$ of patients (3-5). Development of any degree of valve regurgitation in patients with LV dysfunction have a higher mortality risk than those without valve regurgitation (6). This fact alone remains the primary driver for surgery in patients with HVE.

The management of HVE in the 21st century has experienced considerable evolution in relation to the changing patients risk factor profile, demographic characteristics, and the etiology (1,7-9). Higher-risk patients currently include those requiring prosthetic valve replacement, hemodialysis, venous catheters or persons under immunosuppressive therapy as well as intravenous drug users. Moreover, another important concern is represented by the emerging field of cardiac implantable electronic devices (CIEDs) and the transcatheter valve procedure $(1,2)$.

On the other side, the continuing improvement of diagnostic technologies is improving the management of HVE providing detailed information to rapidly take therapeutic decisions. Besides, echocardiography, new advancements in other imaging methods have proved effective in improving HVE management and guide surgical strategy. For example, MRI is useful because it allows to precisely locate abscess cavities especially if a prosthesis is already implanted while the CT imaging associated to metabolic imaging using 18-fluorodeoxyglucose positron emission tomography guarantees a diagnosis both for the embolic complications and the morphological characteristics of the lesion (10-15).

In high-income countries, IE occurs primarily in $\mathrm{n}$ the population over 65 years of age and is sustained by virulent staphylococci. Staphylococcus species and coagulase-negative staphylococci (CoNS) (e.g., Staphylococcus epidermidis, Staphylococcus lugdunensis, and Staphylococcus capitis) have superseded the most common strains of penicillin-sensitive streptococci, typical of the 20th century. However, streptococci remained a pathogen still dangerous in low-income countries $(7,16)$. The lack of randomized trials and the conflicts among European and American guidelines and professional societies recommendations regarding many aspects, such as surgery timing and valve substitutes $(11,17)$, complicate the management of these worrisome infections.

Furthermore, staphylococcal contamination is increasingly characterizing nosocomial infection, which are additionally burdened by antibiotic multiresistance. These concerns have not been resolved by the introduction of 2 vaccines, which unfortunately have failed to show safety and effectiveness in Phase III clinical studies. The first vaccine showed unfavorable results in the prevention of $S$ aureus bacteraemia in patients undergoing hemodialysis, while in the second has been associated to increased mortality in patients undergoing median sternotomy who had a postsurgical staphylococcal infection $(18,19)$. Probably a more specific selection of high-risk patients could better assist preventative medicine research. Individuals most at risk of HVE are those who live more precarious socio-economic conditions and who do not have dental care, intravenous drugs users or alcohol abuser at risk for cardiovascular disease, and individuals with previous cardiac interventions for the treatment of congenital heart disease. It would be interesting to evaluate the effect of a new composite vaccine targeting 5 components of $\mathrm{S}$ aureus on these populations, considering the already promising results in preclinical models (20).

The increased use of long-term intravenous lines and invasive procedures for CIEDs has determined a significant rise in the rate of both left and right side endocarditis, according to the type of device used (21-23). The complications secondary to implantation of CIEDs have also increased and the cost of management of these complications is estimated at over $\$ 15,000$ per patient (24).

The opinion of the surgical community on the best timing to perform an operation for IE is not univocal. While some prefer to take advantage of a two-weeks "cool down" period with antibiotic treatment, others have shown no significant difference in 30-days and 1-year survival in patients undergoing early surgery (within 48 hours) compared with medical therapy $(9,25)$, especially in case of prosthetic valve endocarditis (PVE) (26). The only contraindication to an early intervention is the presence of a neurological complication with potential cerebral hemorrhage (27).

From the surgical perspective several consideration should be made regarding the most adequate technique and valve substitutes to be used in different conditions. Infection localized to valve leaflet might benefit from isolated vegetectomy, while involvement of the valves and nearby structures would require more extensive tissue debridement and replacement with 
prosthetic materials. In the case of significant involvement of the aorto-mitral continuity or periannular abscess, homograft could be used, especially in patients in which the risk of re-infection is a concern or in patients with contraindication to longterm anticoagulation $(9,28)$.

For right sided endocarditis, the options of tricuspid repair or replacement are available. However, the staged procedure of valvectomy as bridge to replacement is an option in patients with persistent sepsis, abscess formation, ongoing drug use, and poor compliance to rehabilitation programs (29). This procedure could indeed represent an acceptable initial bridging therapy for tricuspid valve endocarditis giving time to identify candidates for staged valve replacement (30).

Nevertheless, the lack of specific randomized evidences in surgery for IE and the non-unanimous results from the currently available observational evidences still impede to reach definitive conclusions regarding the best management strategy and more investigations is required to clarify several aspects of IE treatment.

\section{Acknowledgement}

Funding: None.

\section{Footnote}

Provenance and peer review: This article was commissioned by the editorial office, Annals of Translational Medicine for the series "Infective Endocarditis in the 21st Century". The article did not undergo external peer review.

Conflicts of interest: The authors have completed the ICMJE uniform disclosure form (available at http://dx.doi.org/10.21037/ atm-20-4867). The series "Infective Endocarditis in the 21st Century" was commissioned by the editorial office without any funding or sponsorship. FN served as the unpaid Guest Editor of the series and serves as an unpaid editorial board member of Annals of Translational Medicine from Feb 2019 to Jan 2021. CS and CM served as the unpaid Guest Editor of the series. The authors have no other conflicts of interest to declare.

Ethical statement: The authors are accountable for all aspects of the work in ensuring that questions related to the accuracy or integrity of any part of the work are appropriately investigated and resolved.

Open Access Statement: This is an Open Access article distributed in accordance with the Creative Commons AttributionNonCommercial-NoDerivs 4.0 International License (CC BY-NC-ND 4.0), which permits the non-commercial replication and distribution of the article with the strict proviso that no changes or edits are made and the original work is properly cited (including links to both the formal publication through the relevant DOI and the license). See: https://creativecommons.org/licenses/by-nc$\mathrm{nd} / 4.0 \%$.

\section{References}

1. Cahill TJ, Baddour LM, Habib G, et al. Challenges in Infective Endocarditis. J Am Coll Cardiol 2017;69:325-44.

2. Cahill TJ, Prendergast BD. Infective endocarditis. Lancet 2016;387:882-93.

3. Gaca JG, Sheng S, Daneshmand MA, et al. Outcomes for endocarditis surgery in North America: a simplified risk scoring system. J Thorac Cardiovasc Surg 2011;141:98-106.e1062.

4. De Feo M, Cotrufo M, Carozza A, et al. The need for a specific risk prediction system in native valve infective endocarditis surgery. ScientificWorldJournal 2012;2012:307571.

5. Martínez-Sellés M, Muñoz P, Arnáiz A, et al. Spanish Collaboration on Endocarditis-Grupo de Apoyo al Manejo de la Endocarditis infecciosa en ESpaña (GAMES). Valve surgery in active infective endocarditis: a simple score to predict in-hospital prognosis. Int J Cardiol 2014;175:133-7.

6. Baddour LM, Wilson WR, Bayer AS, et al. American Heart Association Committee on Rheumatic Fever, Endocarditis, and Kawasaki Disease of the Council on Cardiovascular Disease in the Young, Council on Clinical Cardiology, Council on 
Cardiovascular Surgery and Anesthesia, and Stroke Council. Infective endocarditis in adults: diagnosis, antimicrobial therapy, and management of complications. Circulation 2015;132:1435-86.

7. Allegranzi B, Bagheri Nejad S, Combescure C, et al. Burden of endemic health-care-associated infection in developing countries: systematic review and meta-analysis. Lancet 2011;377:228-41.

8. Nappi F, Singh SSA, Lusini M, et al. The use of allogenic and autologous tissue to treat aortic valve endocarditis. Ann Transl Med 2019;7:491.

9. Nappi F, Spadaccio C, Dreyfus J, et al. Mitral endocarditis: A new management framework J Thorac Cardiovasc Surg 2018;156:1486-95.e4.

10. Lang RM, Goldstein SA, Kronzon I, et al. ASE's comprehensive echocardiography. 2 ed. Elselvier, 2015.

11. Habib G, Lancellotti P, Antunes MJ, et al. 2015 ESC Guidelines for the management of infective endocarditis: The Task Force for the Management of Infective Endocarditis of the European Society of Cardiology (ESC). Endorsed by: European Association for Cardio-Thoracic Surgery (EACTS), the European Association of Nuclear Medicine (EANM). Eur Heart J 2015;36:3075-128.

12. Chen W, Sajadi MM, Dilsizian V. Merits of FDG PET/CT and Functional Molecular Imaging Over Anatomic Imaging With Echocardiography and CT Angiography for the Diagnosis of Cardiac Device Infections. JACC: Cardiovascular Imaging 2018;11:1679.

13. Ahmed FZ, Arumugam P. 18F-FDG PET/CT now endorsed by guidelines across all types of CIED infection: Evidence limited but growing. J Nucl Cardiol 2019;26:971-4.

14. Akin S, Muslem R, Constantinescu AA, et al. 18F-FDG PET/CT in the Diagnosis and Management of Continuous Flow Left Ventricular Assist Device Infections: A Case Series and Review of the Literature. ASAIO J 2018;64:e11-9.

15. Swart LE, Gomes A, Scholtens AM, et al. Improving the Diagnostic Performance of (18)F-Fluorodeoxyglucose PositronEmission Tomography/Computed Tomography in Prosthetic Heart Valve Endocarditis. Circulation 2018;138:1412-27.

16. Yew HS, Murdoch DR. Global trends in infective endocarditis epidemiology. Curr Infect Dis Rep 2012;14:367-72.

17. Nishimura RA, Otto C, Bonow M, et al. 2017 AHA/ACC Focused Update of the 2014 AHA/ACC Guideline for the Management of Patients With Valvular Heart Disease: A Report of the American College of Cardiology/American Heart Association Task Force on Clinical Practice Guidelines. J Am Coll Cardiol 2017;70:252-89.

18. Shinefield H, Black S, Fattom A, et al. Use of a Staphylococcus aureus conjugate vaccine in patients receiving hemodialysis. N Engl J Med 2002;346:491-6.

19. Fowler VG Jr, Allen KB, Moreira ED, et al. Effect of an investigational vaccine for preventing Staphylococcus aureus infections after cardiothoracic surgery: a randomized trial. JAMA 2013;309:1368-78.

20. Bagnoli F, Fontana MR, Soldaini E, et al. Vaccine composition formulated with a novel TLR7-dependent adjuvant induces high and broad protection against Staphylococcus aureus. Proc Natl Acad Sci 2015;112:3680-5.

21. DeSimone DC, Tleyjeh IM, Correa de Sa DD, et al. Mayo Cardiovascular Infections Study Group. Incidence of infective endocarditis due to viridans group streptococci before and after the 2007 American Heart Association's prevention guidelines: an extended evaluation of the Olmsted County, Minnesota, population and Nationwide Inpatient Sample. Mayo Clin Proc 2015;90:874-81.

22. Mackie AS, Liu W, Savu A, et al. Infective endocarditis hospitalizations before and after the 2007 American Heart Association prophylaxis guidelines. Can J Cardiol 2016;32:942-8.

23. Bikdeli B, Wang Y, Kim N, et al. Trends in hospitalization rates and outcomes of endocarditis among Medicare beneficiaries. J Am Coll Cardiol 2013;62:2217-26.

24. Thornhill MH, Dayer MJ, Forde JM, et al. Impact of the NICE guideline recommending cessation of antibiotic prophylaxis for prevention of infective endocarditis: before and after study. BMJ 2011;342:d2392.

25. Iung B, Doco-Lecompte T, Chocron S, et al. Cardiac surgery during the acute phase of infective endocarditis: discrepancies between European Society of Cardiology guidelines and practices. AEPEI Study Group. Eur Heart J 2016;37:840-8.

26. Lalani T, Chu VH, Park LP, et al. In hospital and 1-year mortality in patients undergoing early surgery for prosthetic valve endocarditis. JAMA Intern Med 2013;173:1495-504.

27. Samura T, Yoshioka D, Toda K, et al. Oscar Study Group. Emergency valve surgery improves clinical results in patients with infective endocarditis complicated with acute cerebral infarction: analysis using propensity score matching†. Eur J Cardiothorac 
Surg 2019;56:942-9.

28. Nappi F, Spadaccio C, Dreyfus J, et al. Mitral endocarditis: A new management framework. J Thorac Cardiovasc Surg 2018;156:1486-95.e4.

29. Pettersson GB, Coselli JS. AATS Surgical Treatment of Infective Endocarditis Consensus Guidelines Writing Committee Chairs. J Thorac Cardiovasc Surg 2017;153:1241-58.e29.

30. Luc JGY, Choi JH, Kodia K, et al. Valvectomy versus replacement for the surgical treatment of infective tricuspid valve endocarditis: a systematic review and meta-analysis. Ann Cardiothorac Surg 2019;8:610-20.

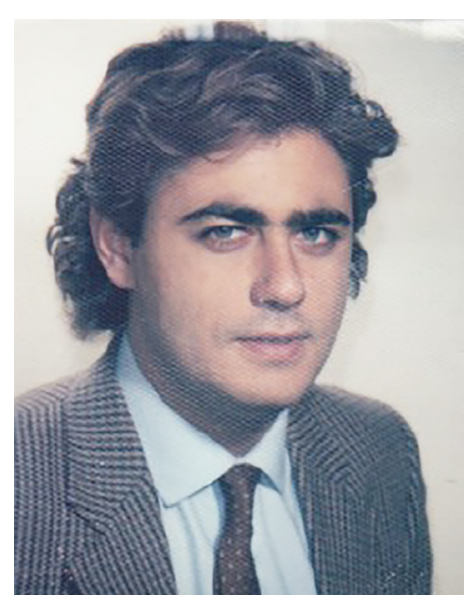

Francesco Nappi

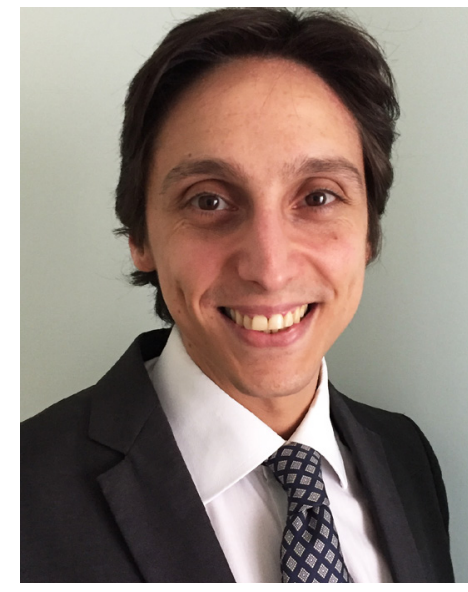

Cristiano Spadaccio

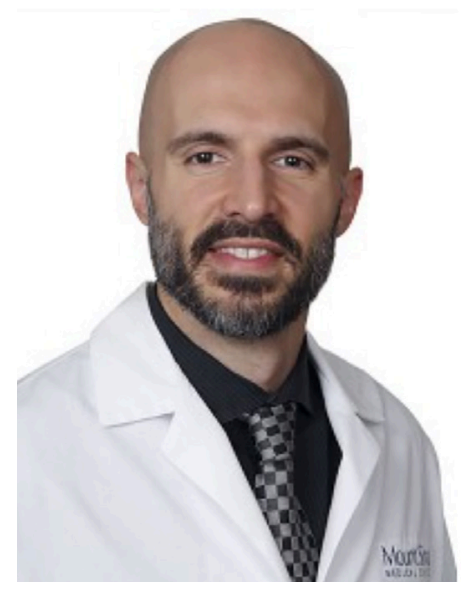

Christos Mihos

Francesco Nappi, MD $^{1}$

(Email: francesconappi2@gmail.com) Cristiano Spadaccio, $\mathbf{M D}, \mathbf{P h D}^{2,3}$ (Email: cristianospadaccio@gmail.com)

Christos Mihos, $\mathrm{DO}^{3}$

(Email:drcmibos@gmail.com)

${ }^{1}$ Department of Cardiac Surgery, Centre Cardiologique du Nord de Saint-Denis, Paris, France;

${ }^{2}$ Department of Cardiac Surgery. Golden Jubilee National Hospital, Glasgow, UK;

${ }^{3}$ Echocardiography Laboratory, Columbia University Division of Cardiology, Mount Sinai Heart Institute, Miami Beach, FL, USA

Submitted Jun 22, 2020. Accepted for publication Jun 30, 2020. doi: $10.21037 / \mathrm{atm}-20-4867$

View this article at: http://dx.doi.org/10.21037/atm-20-4867
Cite this article as: Nappi F, Spadaccio C, Mihos C. Infective endocarditis in the 21th century. Ann Transl Med 2020;8(23):1620. doi: 10.21037/atm-20-4867 